Article

\title{
Maximum Storm Tide Response to the Intensity of Typhoons and Bathymetric Changes along the East Coast of Taiwan
}

\author{
Wen-Cheng Liu', Wei-Bo Chen ${ }^{2,}$, and Lee-Yaw Lin ${ }^{2}$ \\ 1 Department of Civil and Disaster Prevention Engineering, National United University, Miaoli 36063, \\ Taiwan; wcliu@nuu.edu.tw \\ 2 National Science and Technology Center for Disaster Reduction, New Taipei City 23143, Taiwan; \\ wbchen@livemail.tw; yaw@ncdr.nat.tw \\ * Correspondence: wbchen@livemail.tw; Tel.: +886-2-81958612
}

\begin{abstract}
A typhoon-induced storm surge is considered one of the most severe coastal disasters in Taiwan. However, the combination of the storm surge and the astronomical tide called the storm tide can actually cause extreme flooding in coastal areas. This study implemented a two-dimensional hydrodynamic model to account for the interaction between tides and storm surges on the coast of Taiwan. The model was validated with observed water levels at Sauo Fish Port, Hualien Port, and Chenggong Fish Port under different historical typhoon events. The model results are in reasonable agreement with the measured data. The validated model was then used to evaluate the effects of the typhoon's intensity, bathymetric change, and the combination of the typhoon's intensity and bathymetric change on the maximum storm tide and its distribution along the east coast of Taiwan. The results indicated that the maximum storm tide rises to $1.92 \mathrm{~m}$ under a typhoon with an intensity of a 100-year return period. The maximum storm tide increased from a baseline of $1.26 \mathrm{~m}$ to $2.63 \mathrm{~m}$ for a $90 \%$ bathymetric rise at Sauo Fish Port under the conditions of Typhoon Jangmi (2008). The combination of the intensity of a typhoon with a 100-year return period and a 90\% bathymetric rise will result in a maximum storm tide exceeding $4 \mathrm{~m}, 2 \mathrm{~m}$, and $3 \mathrm{~m}$ at Sauo Fish Port, Hualien Port, and Chenggong Fish Port, respectively. We also found that the distribution of the maximum storm tide on the east coast of Taiwan can expand significantly subject to the bathymetric rise.
\end{abstract}

Keywords: maximum storm tide; two-dimensional tide-surge modeling system; east coast of Taiwan; intensity of typhoon; bathymetric rise.

\section{Introduction}

Storm surges are a result of low-pressure weather systems (cyclones), creating suction over the covered area of the ocean, and the strong winds that are usually present in storms. High sea levels and strong forces, including low pressure, heavy wind, and wave set-up, directly influence humans, property, and habitats by over-topping sea dikes. Storm surges may even cause loss of life; damage; and the loss of habitat, useful land, property, infrastructure, and services [1-3].

Storm surge modeling is an important tool for operational flood forecasting systems and flood hazard assessments, particularly for understanding the risks from these moderate to severe storms that have occurred only a few times. In the past, the simplest method of forecasting the maximum storm surge was to use an empirical formula $[4,5]$. Conventional studies on the storm tide or storm surge and the astronomic tide and storm surge were individually simulated and then superposed. However, the interaction caused by the tide and storm surge might be neglected [6]. Today, the numerical models of storm surges have been widely applied to predict the surge tides [7-13]. For example, $\mathrm{Xu}$ et al. [14] integrated Monte Carlo and hydrodynamic models to estimate extreme water levels that occurred as a consequence of a storm surge. Murty et al. [15] coupled wave and surge hydrodynamic modeling systems to simulate the storm surge, water level elevation, and wave 
induced setup with 'Phailin', a very severe cyclonic storm that made landfall in Odisha State on the east coast of India in October 2013. Marujo et al. [16] adopted the advanced circulation model (ADCIRC) to investigate the ability of ADCIRC to model the storm surge that occurred in Viana do Castelo (Portugal) on 14-17 October 1987. Drews and Galarneau [17] examined the storm surge in New York Harbor using the Weather Research and Forecasting (WRF) atmospheric model and the Coupled-Ocean-Atmosphere-Wave-Sediment transport/Regional Ocean Modeling System (COAWST/ROMS). They presented a new technique using a directional analysis to calculate and display maps of a coastline's potential for a storm surge. Zhang and Sheng [18] investigated the extreme sea levels of the 50-year return period associated with storm surges and tides over the Northwest Pacific Ocean using a two-dimensional ocean circulation model. The model forcing included surface wind stress and atmospheric pressure at sea level obtained from the Climate Forecast System Reanalysis fields at 6-hour intervals. Arns et al. [19] assessed the impact of the mean sea level rise on extreme water levels using a numerical tide-surge model that covered the entire North Sea, whereas the bathymetric resolution was highest in the German Bight. Zhang et al. [20] investigated the effect of angular deviations in the forecasted typhoon track on the storm surge height. The simulated results revealed that the uncertainty of the forecasted typhoon track is an important factor to affect the accuracy of storm surge predictions.

To accurately simulate and appropriately describe the physics of storm surges, a hydrodynamic model must treat costal features that can significantly affect the generation and propagation of the storm surge. Therefore, the model domain should incorporate complex costal bathymetry and topography. Shen et al. [21] reported that with the use of unstructured grids, a finite difference model often represented the irregular coastal morphological features better than finite difference models. However, its computational speed is restricted by the stability condition when a very fine resolution grid is used. In this context, a storm surge model that can resolve complex coastal morphological features and maintain computation efficiency is required.

The main objective of this study focuses on the investigation of the maximum storm tide along the east coast of Taiwan with an unstructured grid, two-dimensional hydrodynamic model. The model was validated against the observed water levels at different gauge stations for different historical typhoon events. The validated model was then applied to investigate the maximum storm tide response to a typhoon's intensity and bathymetric change.
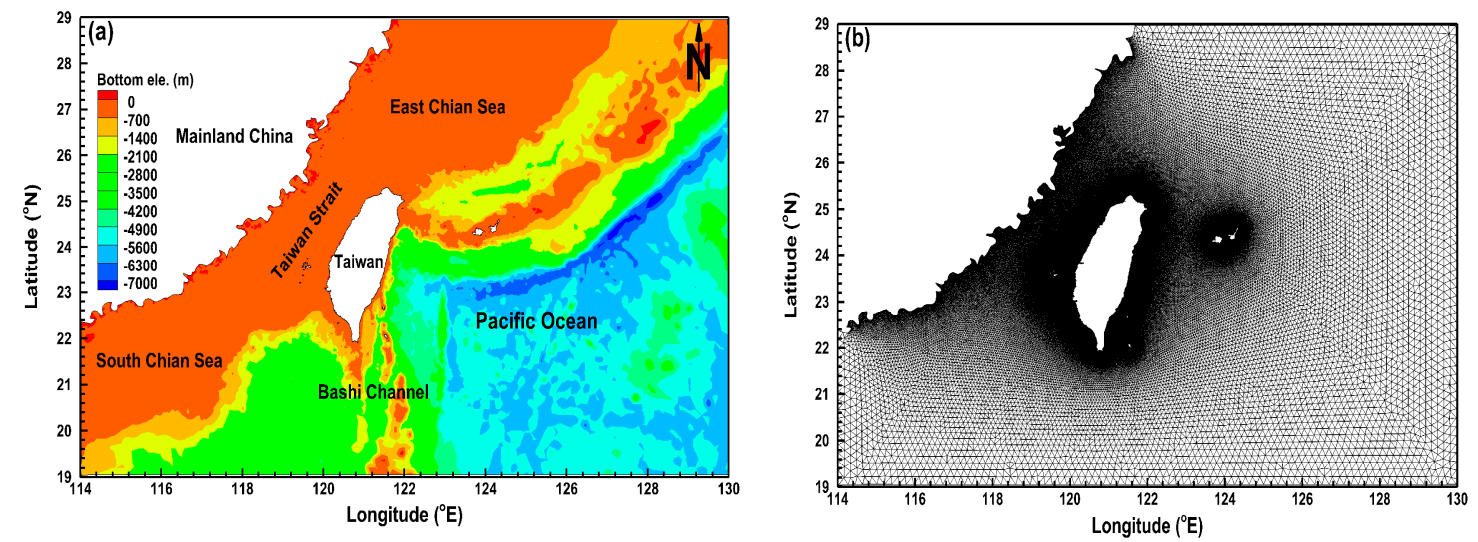

Figure 1. (a) Bathymetry and (b) unstructured grids of the computational domain. 


\section{Description of the Study Area}

The computational domain covers the region between the longitude of $114^{\circ} \mathrm{E}$ to $130^{\circ} \mathrm{E}$ and the latitude of $19^{\circ} \mathrm{N}$ to $29^{\circ} \mathrm{N}$. This area is composed of the Western Pacific Ocean, the Taiwan Strait, the South China Sea, and the East China Sea, which are located to the east, west, south, and north of Taiwan, respectively (Figure 1a). The bathymetric data were obtained from coastal digital elevation models (DEMs), ETOPO1, and a global relief model. ETOPO1 integrates land topography and the ocean bathymetry of the Earth's surface with 1 arc-minute resolution [22]. Figure 1a also shows the bottom elevations for the hydrodynamic model. The bathymetries on the east coast of Taiwan are quite steep. The bottom elevations rapidly vary from several meters at the shoreline to several thousand meters at a distance of $10 \mathrm{~km}$ from the coast. A total of 278,630 triangular cells and 142,041 non-overlapping unstructured grids were used in the horizontal plane to fit the complex shoreline of Taiwan and its adjacent small islands. The mesh resolution ranges from $30 \mathrm{~km}$ to $300 \mathrm{~m}$. The fine meshes were around the coast of Taiwan and its offshore islands while the coarse meshes were along the boundary of the open ocean (Figure 1b). A time step of $60 \mathrm{~s}$ was used in the simulations with no signs of numerical instability for this model grid system.

\section{Methodology}

\subsection{Hydrodynamic Model}

The coastal hydrodynamic model, SELFE [23], was applied to compute the tide and storm surge along the coast of Taiwan. SELFE is the Semi-implicit Eulerian-Lagrangian finite-element model and has been widely used for simulating tsunami propagation [24], assessing water quality and ecosystem dynamics [25], evaluating oil spill dynamics [26], generating inundation maps [27], and inundation modeling of extreme river flow, typhoons, and hurricanes [28,29].

The SELFE used in the present study is a two-dimensional vertically integrated version (SELFE-2D). The government equations in two-dimensional form are given as:

$$
\begin{gathered}
\frac{\partial \eta}{\partial t}+\frac{\partial u H}{\partial x}+\frac{\partial v H}{\partial y}=0 \\
\frac{D u}{D t}=f v-\frac{\partial}{\partial x}\left\{g(\eta-\alpha \hat{\psi})+\frac{P_{A}}{\rho_{0}}\right\}+\frac{\tau_{s x}-\tau_{b x}}{\rho_{0} H} \\
\frac{D v}{D t}=-f u-\frac{\partial}{\partial y}\left\{g(\eta-\alpha \hat{\psi})+\frac{P_{A}}{\rho_{0}}\right\}+\frac{\tau_{s y}-\tau_{b y}}{\rho_{0} H}
\end{gathered}
$$

where $\eta(x, y, t)$ is the free-surface elevation; $H=\eta+h, h$ is the bathymetric depth; $u(x, y, t)$ and $v(x, y, t)$ are the horizontal velocity in the $x, y$ directions, respectively; $f$ is the Coriolis factor; $g$ is the acceleration due to gravity; $\hat{\psi}$ is the earth's tidal potential; $\alpha$ is the effective earth elasticity factor; $\rho_{0}$ is the reference density of the water; and $P_{A}(x, y, t)$ is the atmospheric pressure at the free surface.

The variables, $\tau_{s x}$ and $\tau_{s y}$, are the wind stress in the $x$ and $y$ directions, respectively, which can be expressed as:

$$
\begin{aligned}
& \tau_{s x}=\rho_{a} C_{s} \sqrt{\left(W_{x}+W_{y}\right)^{2}} W_{x} \\
& \tau_{s y}=\rho_{a} C_{s} \sqrt{\left(W_{x}+W_{y}\right)^{2}} W_{y}
\end{aligned}
$$

where $C_{s}$ is the wind drag coefficient; $\rho_{a}$ is the air density; and $W_{x}, W_{y}$ are the wind speed in the $x, y$ components, respectively. The wind drag coefficient, $C_{s}$, is given by Large and Pond [30] and Powell et al. [31]. 


$$
C_{s}=\left\{\begin{array}{c}
0.00114, W \leq 10 \mathrm{~m} / \mathrm{s} \\
(0.49+0.0065 W) \times 10^{-3}, 10 \mathrm{~m} / \mathrm{s}<W \leq 38 \mathrm{~m} / \mathrm{s} \\
0.003, W>38 \mathrm{~m} / \mathrm{s}
\end{array}\right.
$$

$\tau_{b x}$ and $\tau_{b y}$ are the bottom shear stress in the $x$ and $y$ directions, respectively. The bottom friction force is given by a quadratic drag law:

$$
\begin{gathered}
\tau_{b x}=\rho_{0} C_{b} \sqrt{u^{2}+v^{2}} u \\
\tau_{b y}=\rho_{0} C_{b} \sqrt{u^{2}+v^{2}} v
\end{gathered}
$$

where $C_{b}$ is the bottom drag coefficient and will be determined through the validation of the model.

\subsection{Global Model for the Prediction of Ocean Tides}

For many practical applications of modeling in the coastal environment, accurate predictions of tidal currents or elevations are always indispensable. Due to the necessity of simulating the interaction between astronomical tides and storm surges, the driving forces at the open boundaries of the hydrodynamic model are tidal elevations. In the present study, a global ocean tidal prediction model, TPXO, which was developed by scholars at the Oregon State University, was adopted to extract tidal harmonic constants and then specify the open boundaries of SELFE-2D for simulating the tidal propagation. TPXO uses inverse theory and assimilated measured data from tidal gauges and the TOPEX/Poseidon satellite to achieve the optimum balance between observations and hydrodynamics. The extracted tidal harmonic constants provided complex amplitudes of the earth-relative sea-surface elevation for eight primary tidal constituents (i.e., $\mathrm{M}_{2}, \mathrm{~S}_{2}, \mathrm{~N}_{2}, \mathrm{~K}_{2}, \mathrm{~K}_{1}, \mathrm{O}_{1}, \mathrm{P}_{1}$, and $\mathrm{Q}_{1}$ ). The detailed methodologies used to compute the tides in TPXO can be found in Egbert et al. [32] and Egbert and Erofeeva [33].

\subsection{Parametric Cyclone Model}

The meteorological boundary conditions for storm surge calculations consist of the wind fields and atmospheric pressure of the typhoon. In practice, a common way to generate the wind fields and air pressure fields of typhoons is to reconstruct them using the analytical parametric cyclone model. Over the years, many parametric cyclone models have been developed to provide meteorological information for storm surge modeling [34-38]. Jakobsen and Madsen [39] investigated and compared parametric cyclone models based on the cyclone position, central pressure, maximum wind speed, and radius to maximum wind speed. They found that the analytical models provide very similar air pressure and tangential wind speed distributions for a cyclone. Therefore, a parametric cyclone model presented by Holland [35] was employed:

$$
\begin{gathered}
P_{A}=P_{c}+\left(P_{n}-P_{c}\right) \exp \left[\left(\frac{R_{\max }}{r}\right)^{B}\right] \\
W=\sqrt{\frac{B\left(P_{n}-P_{c}\right)}{\rho_{a}}\left(\frac{R_{\max }}{r}\right)^{B} \exp \left(-\frac{R_{\max }}{r}\right)^{B}+\left(\frac{r f}{2}\right)^{2}}-\left(\frac{r f}{2}\right),\left[\begin{array}{l}
W_{x} \\
W_{y}
\end{array}\right]=\left[\begin{array}{l}
-W \sin \theta \\
W \cos \theta
\end{array}\right]
\end{gathered}
$$

where $P_{A}$ is the air pressure; $P_{n}$ is the ambient pressure; $P_{c}$ is the central air pressure of the typhoon; $R_{\max }$ is the radius to maximum wind speed; $r$ is the radial distance from typhoon center; $W$ is the wind speed; $\rho_{a}$ is the air density; $f$ is the Coriolis factor; $W_{x}, W_{y}$ are the wind speeds in the $x, y$ components, respectively; $\theta$ is the azimuthal angle with respect to the typhoon's eye; and $B$ is a parameter that characterizes the scale of the typhoon. The formula of $B=1.5+\left(980-P_{c}\right) / 120$ presented by Hubbert et al. [40] was adopted.

\subsection{Methods for Frequency Analysis}


To estimate the minimum central pressure with different return periods, two approaches for frequency analysis, the Gumbel distribution [41] and the Weibull distribution [42], were adopted for analyzing the extreme values. The formulas can be represented as:

1. Gumbel distribution

$$
\begin{gathered}
f(x)=\frac{1}{\sigma} \exp \left[-\frac{x-\xi}{\sigma}-\exp \left(-\frac{x-\xi}{\sigma}\right)\right], \quad-\infty<x<+\infty \\
F(x)=\exp \left[-\exp \left(-\frac{x-\xi}{\sigma}\right)\right]
\end{gathered}
$$

2. Weibull distribution:

$$
\begin{gathered}
f(x)=\frac{\alpha}{\beta}\left(\frac{x}{\beta}\right)^{\alpha-1} \exp \left(-\left(\frac{x}{\beta}\right)^{\alpha}\right), 0 \leq x<+\infty \\
F(x)=1-\exp \left(-\left(\frac{x}{\beta}\right)^{\alpha}\right)
\end{gathered}
$$

where $x$ is the sample variables; $f(x)$ is the probability density function; $F(x)$ is the cumulative probability function; $\sigma$ is the scale parameter; $\xi$ is the local parameter; $\alpha$ is the shape parameter $(\alpha>0)$; and $\beta$ is the scale parameter of the distribution $(\beta>0)$. The formula for calculating the difference between the ambient and typhoon central pressure, $\Delta P_{c}$, that corresponds to each return period can be expressed as:

$$
T=\frac{1}{1-F(x)}
$$

where $T$ is the return period.

\subsection{Indicators of Mode Performance}

Three criteria are adopted to evaluate the model performance for water level simulation. The criteria are the mean absolute error (MAE), the root mean square error (RMSE), and percent bias (PBIAS) [43]. The optimal value of PBIAS is 0 with low-magnitude values, indicating accurate simulations of the model. Positive values of PBIAS indicate that the model overestimates the water level, while negative values indicate that the model underestimates the water level [44]. The equations for these three criteria are shown as follows:

$$
\begin{aligned}
M A E & =\frac{1}{N} \sum_{i=1}^{N}\left|\eta_{i}^{s}-\eta_{i}^{m}\right| \\
R M S E & =\sqrt{\frac{1}{N} \sum_{i=1}^{N}\left(\eta_{i}^{s}-\eta_{i}^{m}\right)^{2}} \\
P B I A S & =\frac{\sum_{i=1}^{n} \eta_{i}^{s}-\eta_{i}^{m}}{\sum_{i=1}^{n} \eta_{i}^{m}} \times 100
\end{aligned}
$$

where $\eta_{i}^{s}$ is the simulated water level, and $\eta_{i}^{m}$ is the measured water level.

\section{Model Validation}

To confirm the model's capability and ability to simulate storm tides along the east coast of Taiwan, ten historical typhoon events, including Typhoon Tim (1994), Typhoon Bilis (2000), Typhoon Nockten (2004), Typhoon Kaemi (2006), Typhoon Sepat (2007), Typhoon Krosa (2007), Typhoon Fungwong (2008), Typhoon Jangmi (2008), Typhoon Sinlaku (2008) and Typhoon Fanapi (2010), were used for validating the two-dimensional hydrodynamic model. The tracks of these ten 
typhoons are shown in Figure 2. To make the comparison of water levels between the simulation and observations, three tide gauge stations, Sauo Fish Port, Hualien Port, and Chenggong Fish Port, which are located on the east coast of Taiwan, were selected for the model validation. Figure 2 also illustrates the locations of the tidal gauge stations and their corresponding four typhoon events for the model validation. The observed water levels of the four typhoons at each tidal gauge station were used to validate the hydrodynamic model.
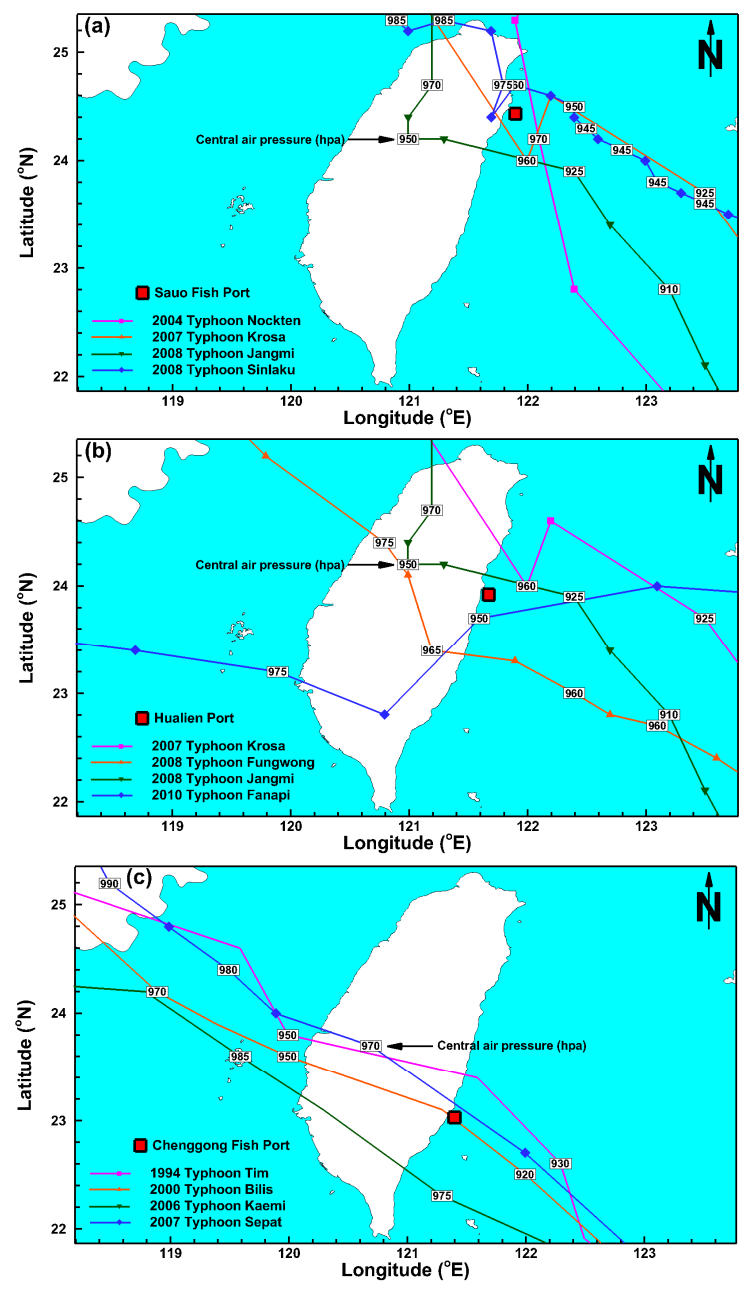

Figure 2. Tracks of typhoons for model validation and their corresponding tide gauge stations at (a) Sauo Fish Port, (b) Hualien Port, and (c) Chenggong Fish Port.

The information of the track and central pressure of the ten typhoon events used to construct the wind and air pressure fields can be obtained from the Regional Specialization Meteorological Center (RSMC) Tokyo-Typhoon Center best track database. The hourly water level data measured at three tide gauge stations was provided by the Central Weather Bureau (CWB). Figures 3-5 present the model-data comparisons of the water levels for different typhoon events at Sauo Fish Port (Figure 3), Hualien Port (Figure 4), and Chenggong Fish Port (Figure 5). The water level hydrographs indicate that the simulations have good agreement with the observations for both astronomical tides and storm tides, except at Hualien Port during Typhoon Jangmi (2008) (Figure 4c). The model simulations underestimated the water level around the maximum storm tide, and these underestimations may be due to the inaccuracy of the wind and air pressure fields provided by the parametric cyclone model. The parametric cyclone model is sometimes difficult to use to represent the structure of the typhoon well at a certain location around landfall. Feng et al. [45] adopted Jelesnianski's circular hurricane model, which was composed of a circular wind field combined with a hurricane moving speed, to simulate storm surges at Tianjin, China. They also 
found a similar problem regarding the inaccuracy of the wind and air pressure forcing. The statistical errors for the differences between the simulated and observed water levels at the three tidal gauge stations can be found in Table 1 . The maximum MAE, RMSE, and PBIAS are $0.14 \mathrm{~m}, 0.17$ $\mathrm{m}$, and $-11.46 \%$, respectively, at Hualien Port. Figure 6 shows the comparison of the simulated and measured maximum storm tides for historical typhoon events at three tide gauge stations. The maximum storm tides for simulation and measurement are $1.49 \mathrm{~m}$ and $1.41 \mathrm{~m}$, respectively, and occurred at Chenggong Fish Port during Typhoon Bilis (2000) (Figure 6c). The maximum difference between the simulations and measurements of the maximum storm tide is $0.09 \mathrm{~m}$ (Figure $6 \mathrm{c}$ ) and also occurred at Chenggong Fish Port for Typhoon Kaemi (2006). The phase error between the simulated and measured maximum storm tide is $1 \mathrm{~h}$ (i.e., lag $1 \mathrm{~h}$, Figure 6b) at Hualien Port during Typhoon Krosa (2007) and Typhoon Fungwong (2008). Overall, the simulated results quantitatively agree with the observations of astronomical tides and storm surges. Throughout the model validation procedure, the bottom drag coefficient was set to 0.005 .
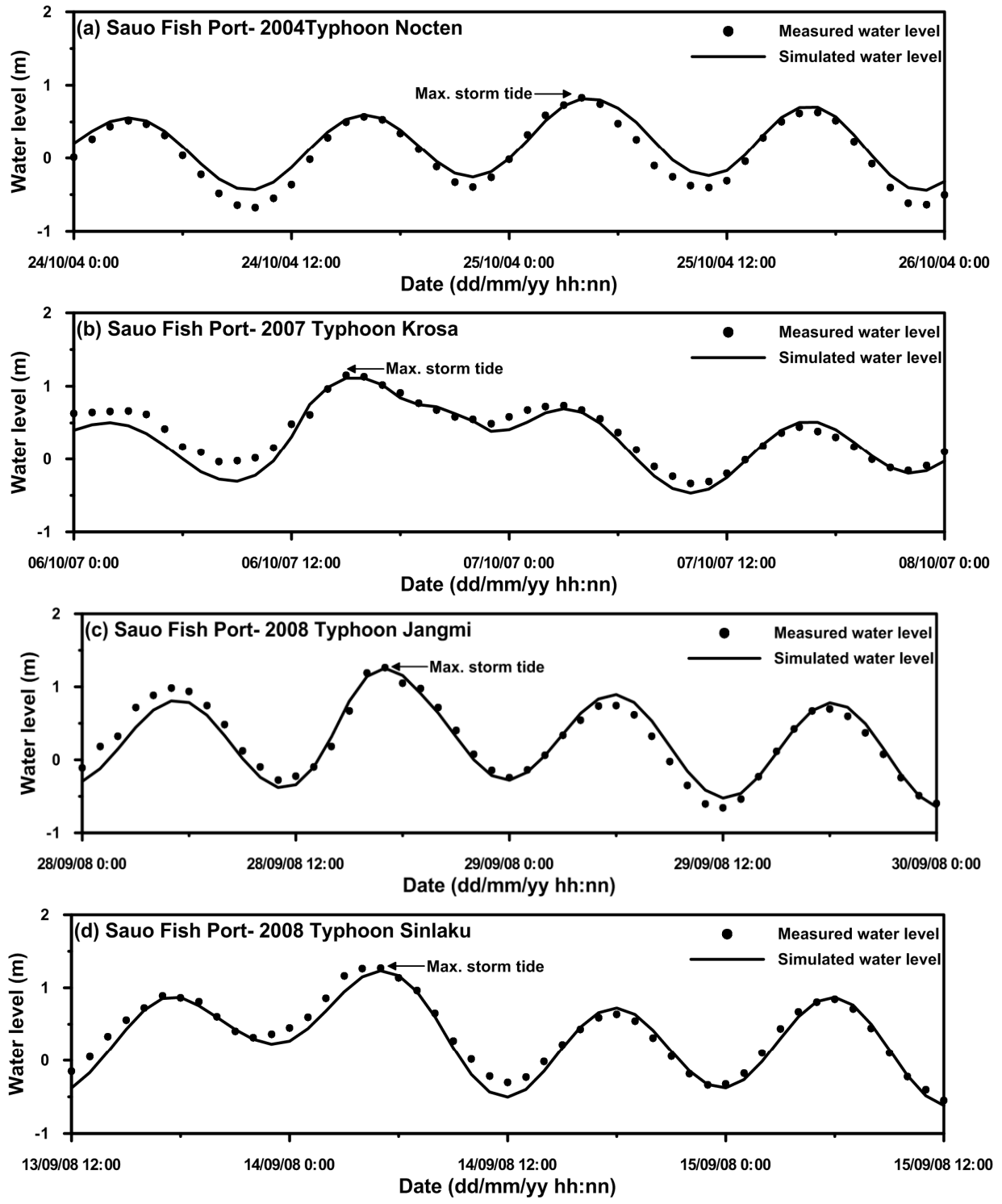

Figure 3. Model-data comparison of water level hydrographs at Sauo Fish Port for (a) Typhoon Nockten, (b) Typhoon Krosa, (c) Typhoon Jangmi, and (d) Typhoon Sinlaku. 

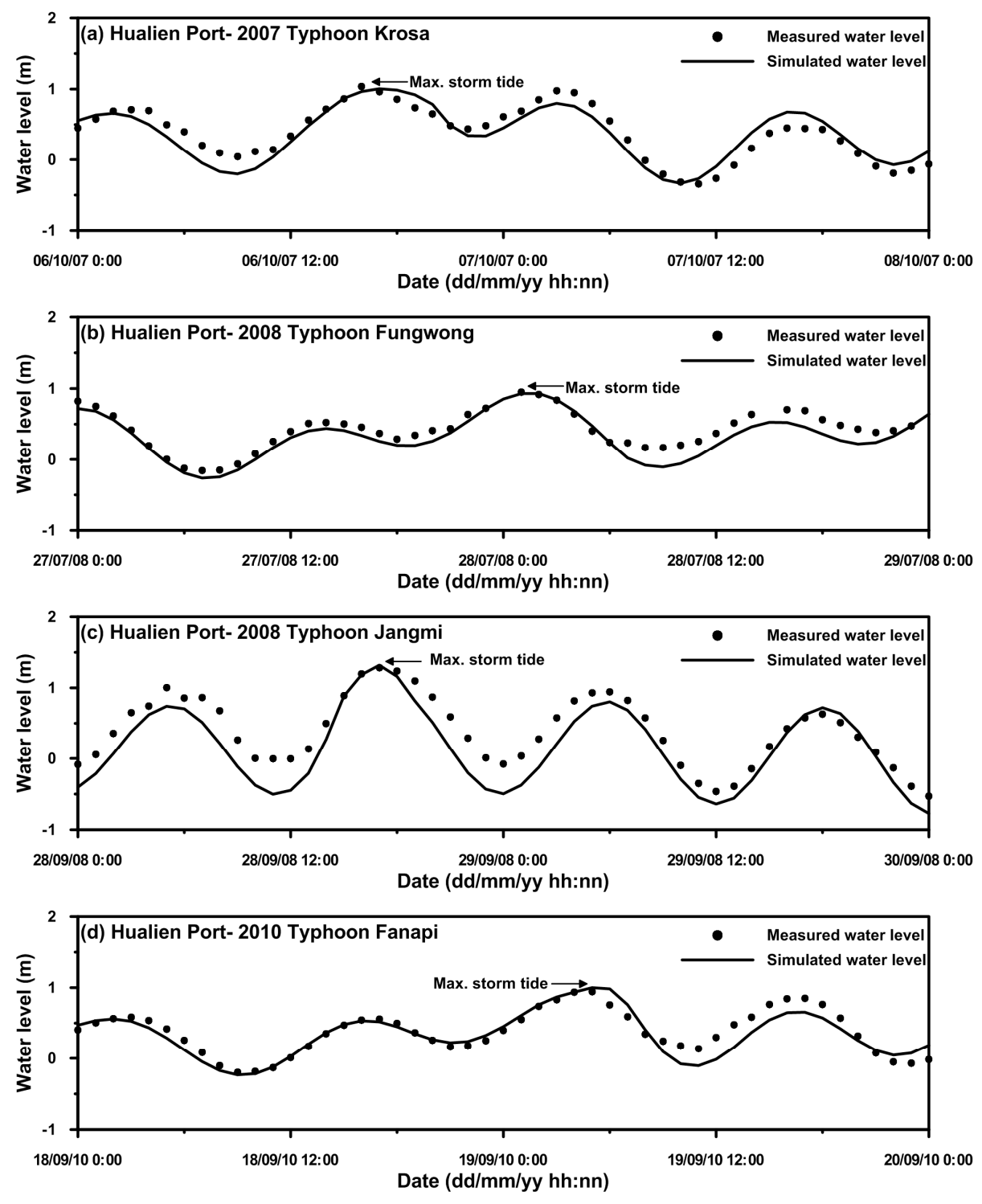

Figure 4. Model-data comparison of water level hydrographs at Hualien Port for (a) Typhoon Krosa, (b) Typhoon Fungwong, (c) Typhoon Jangmi, and (d) Typhon Fanapi.

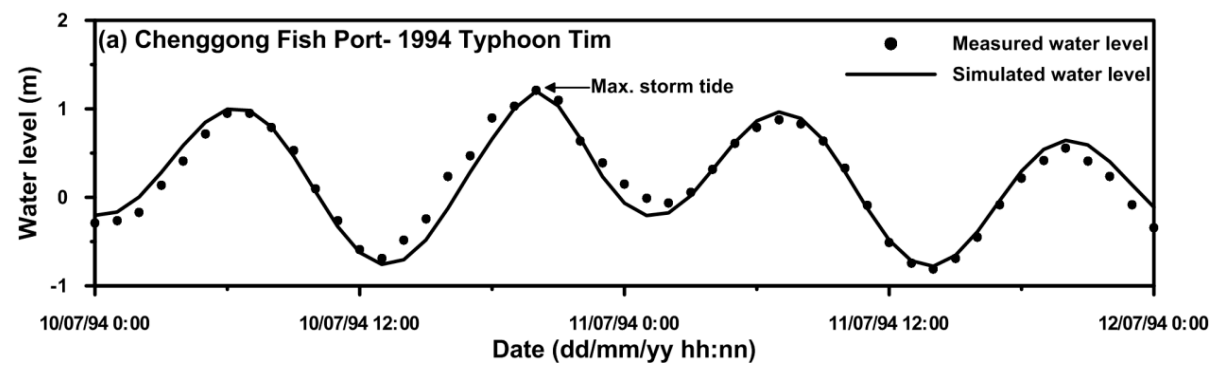



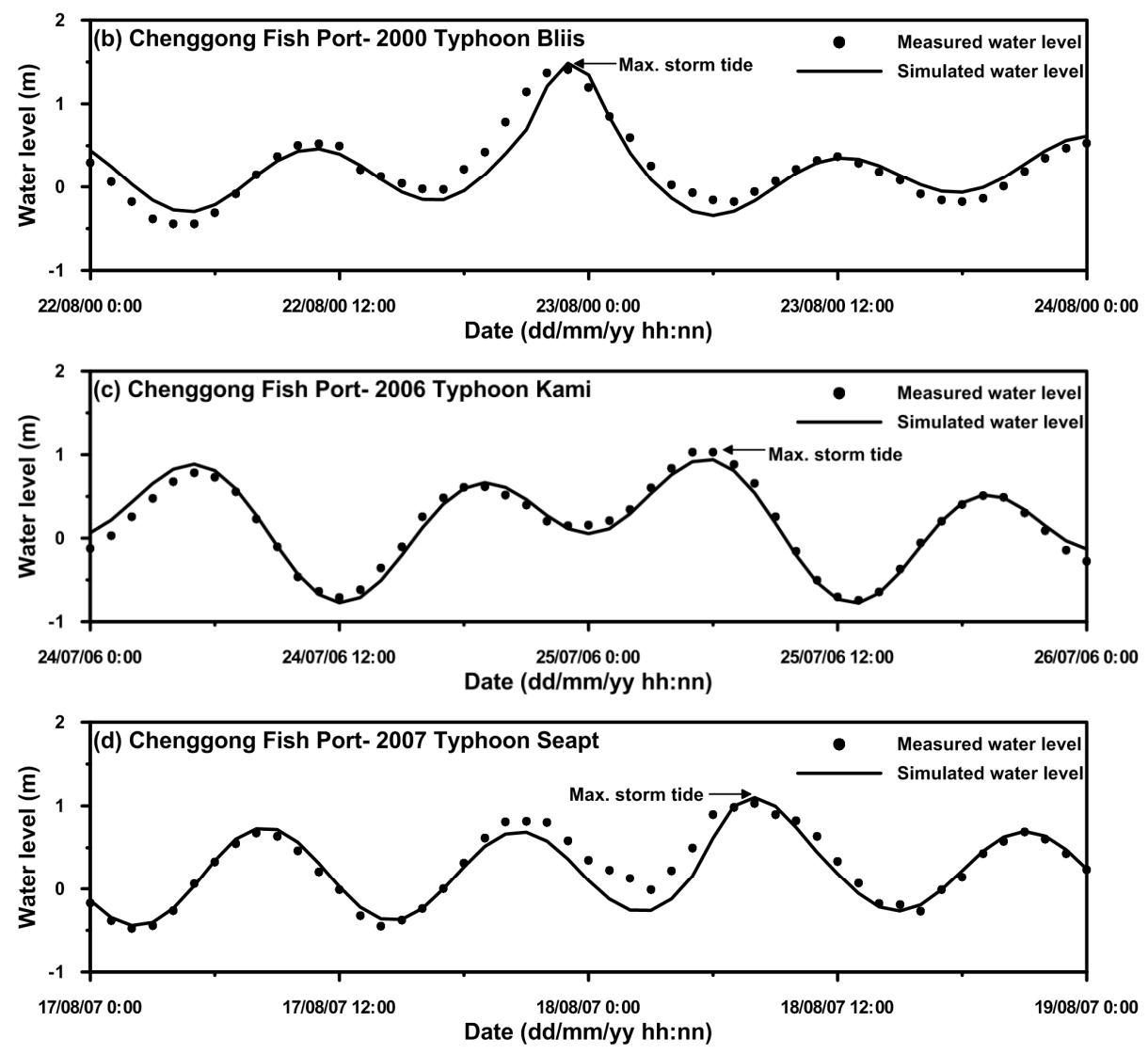

Figure 5. Model-data comparison of water level hydrographs at Chenggong Fish Port for (a) Typhoon Tim, (b) Typhoon Bilis, (c) Typhoon Kaemi, and (d) Typhon Sepat.
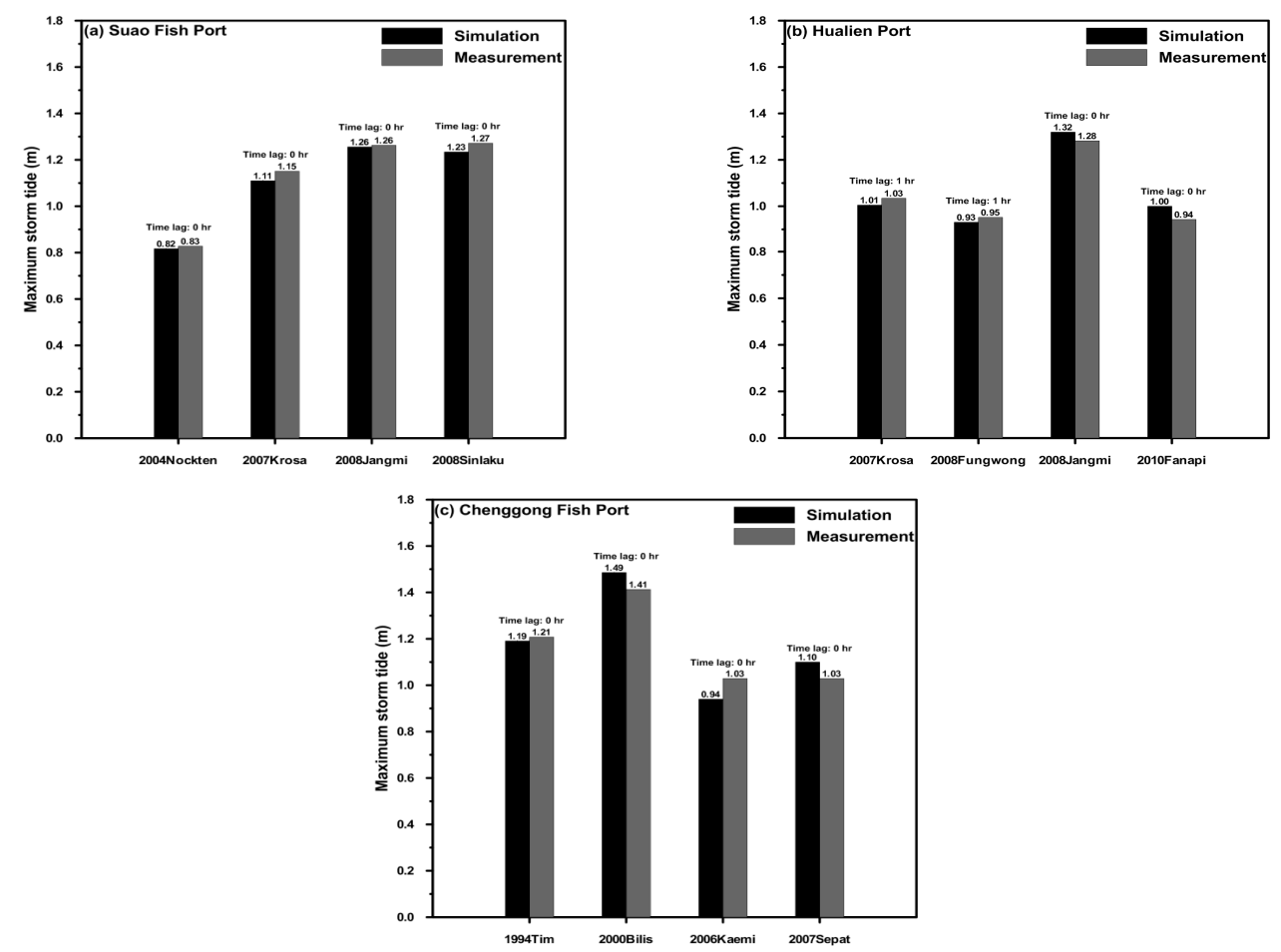

Figure 6. Model-data comparison of maximum storm tides for different typhoon events at (a) Sauo Fish Port, (b) Hualien Port, and (c) Chenggong Fish Port. 
10 of 19

Table 1. Statistical error between simulated and measured water levels.

\begin{tabular}{cccc}
\hline Station & MAE $(\mathrm{m})$ & RMSE $(\mathrm{m})$ & PBIAS $(\%)$ \\
\hline Sauo Fish Port & 0.14 & 0.16 & -8.23 \\
Hualien Port & 0.14 & 0.17 & -11.46 \\
Chenggong Fish Port & 0.14 & 0.17 & -10.54 \\
\hline
\end{tabular}

\section{Modeling Investigation and Discussion}

Two typhoon events, Typhoon Bilis (2000) for Chenggong Fish Port and Typhoon Jangmi (2008) for Sauo Fish Port and Hualien Port, induced maximum storm tides and were selected as baseline typhoon events to investigate the influence of a typhoon's intensity and bathymetric change on the maximum storm tide and storm tide distribution.

\subsection{Maximum Storm Tide Response to Typhoon's Intensity}

To determinate a valid intensity of a typhoon, i.e., the minimum central pressure, the typhoon events that passed Taiwan within a distance of $50 \mathrm{~km}$ from 1994 to 2014 were adopted, and the annual minimum central pressure was then selected for an extreme value analysis. Based on the frequency analysis methods, the parameters, $\sigma, \xi, \alpha$, and $\beta$ are estimated to be 14.911, 73.357, 4.434, and 88.15, respectively, for the Gumbel distribution and the Weibull distribution in Eqs. (9)-(12).

Figure 7 illustrates the relationship between the cumulative probability and pressure difference between the ambient pressure $(1013.25 \mathrm{mb})$ and the central pressure of a typhoon, $\Delta P_{c} \quad\left(\Delta P_{c}=1013.25-P_{c}\right)$, using the Weibull distribution and Gumbel distribution. Figure 7 shows that the correlation coefficient $(\mathrm{R}=0.99)$ from the Weibull distribution is higher than that from the Gumbel distribution ( $\mathrm{R}=0.97)$; thus, the frequency analysis method using Weibull distribution is selected as the suitable approach for the present study. Table 2 indicates that the values of $\Delta P_{c}$ under different return periods depended on the frequency analysis. Table 2 shows that the $\Delta P_{c}$ values sequentially increase by $2 \mathrm{mb}$ only for the 100-year, 150-year, and 200-year return periods. Therefore, the $\Delta P_{c}$ values for the 20-year, 50-year, and 100-year return periods were used in following simulations, and their corresponding central pressure $\left(P_{c}\right)$ values are $900.35 \mathrm{mb}, 893.35$ $\mathrm{mb}$, and $888.85 \mathrm{mb}$, respectively (see Table $2, P_{c}=1013.25-\Delta P_{c}$ ). These three central pressure values combined with the fixed track paths, Typhoon Bilis (2000) and Typhoon Jangmi (2008), were used for different scenario simulations.

The simulated maximum storm tides under baseline, 20-year, 50-year, and 100-year return periods are shown in Figure 8. Note that the simulated maximum storm tides at the gauge stations at Sauo Fish Port and Hualien Port adopt the track path of Typhoon Jangmi (2008), while the simulated maximum storm tide at Chenggong Fish Port applies the track path of Typhoo Bilis (2000). Compared to baseline and the 20-year return period, the simulated maximum storm tide significantly increased. However, the increment of the maximum storm tide with the changes in central pressures with the 20-year, 50-year, and 100-year return periods is small. The small increment may be the reason that the central air pressure of typhoons for the 20-year, 50-year, and 100-year return periods is similar (Table 2). Compared to baseline and the central pressure of the 100 -year return period, the maximum increment of the maximum storm tide is only $0.57 \mathrm{~m}$ at Hualien Port (Figure 8).

Figure 9 shows the water level hydrographs for Sauo Fish Port, Hualien Port, and Chenggong Fish Port under baseline and $\Delta P_{c}$ specified with different return periods. It indicates that the water level increases as increasing the return period. The figure also shows the phase shift of maximum storm tide under baseline and $\Delta P_{c}$ specified with different return periods at the Sauo Fish Port (Figure 9a) and Hualien Port (Figure 9b) during Typhoon Jangmi (2008), while the phase keeps the 
same at maximum storm tide at the Chenggong Fish Port during Typhoon Bilis (2000). It is the reason that the track of Typhoon Jangmi (2008) passes through the path between Sauo Fish Port and Hualien Port (see Figures $2 \mathrm{a}$ and $2 \mathrm{~b}$ ) and the storm tide is significantly influenced by wind stress at these two stations. As the $\Delta P_{c}$ value increases (i.e. $P_{c}$ decreases), the radius of maximum wind speed $\left(R_{\max }\right)$ decreases, resulting in stronger wind stress $[46,47]$ to alter the phase of maximum storm tide. The track of Typhoon Bilis (2000) passes through the Chenggong Fish Port (see Figure 2c). The storm tide is mainly affected by air pressure therefore the phase of maximum storm tide keeps the same for baseline and different return periods (Figure 9c).

In general, air pressure affects the storm surge by the way of inverse barometer [48]. The effect of the air pressure is only evident near the typhoon center where the minimum air pressure occurs. Feng et al. [45] used the Advanced Circulation model (ADCIRC) to investigate the sensitivity of Tianjin storm surge to the four paths using the validated storm surge simulation system and found that the hurricane path had significant influence on storm surge height. In the current study, the path of Typhoon Bilis (2000) closely approached to Chenggong Fish Port resulting in highest maximum storm tide under the conditions of baseline and different return periods (see Figure 8).

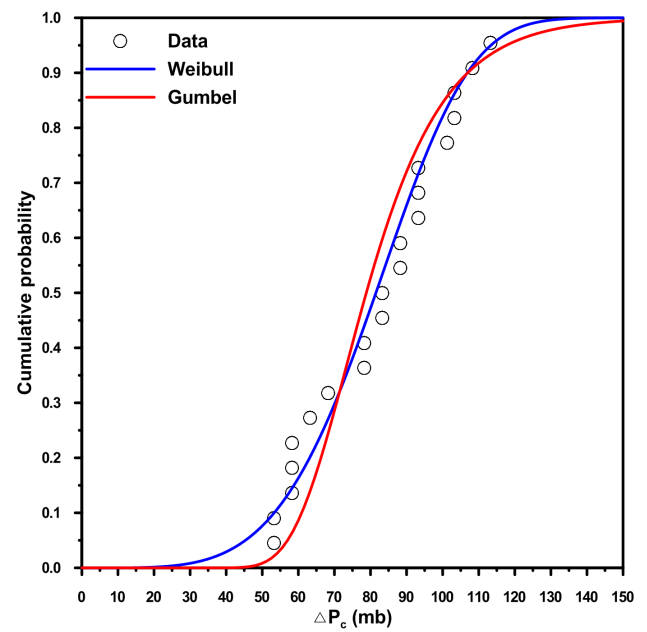

Figure 7. The relationship between the cumulative probability and pressure difference $\left(\Delta P_{c}\right)$ using different frequency analysis models (i.e., the Gumbel distribution and Weibull distribution).

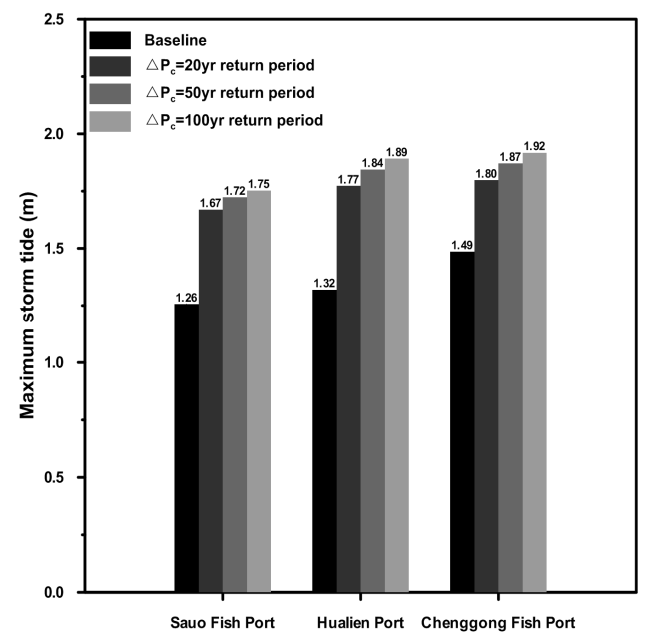

Figure 8. The comparison of the simulated maximum storm tide under baseline, 20-year, 50-year, and 100-year return periods at different tide gauge stations. 

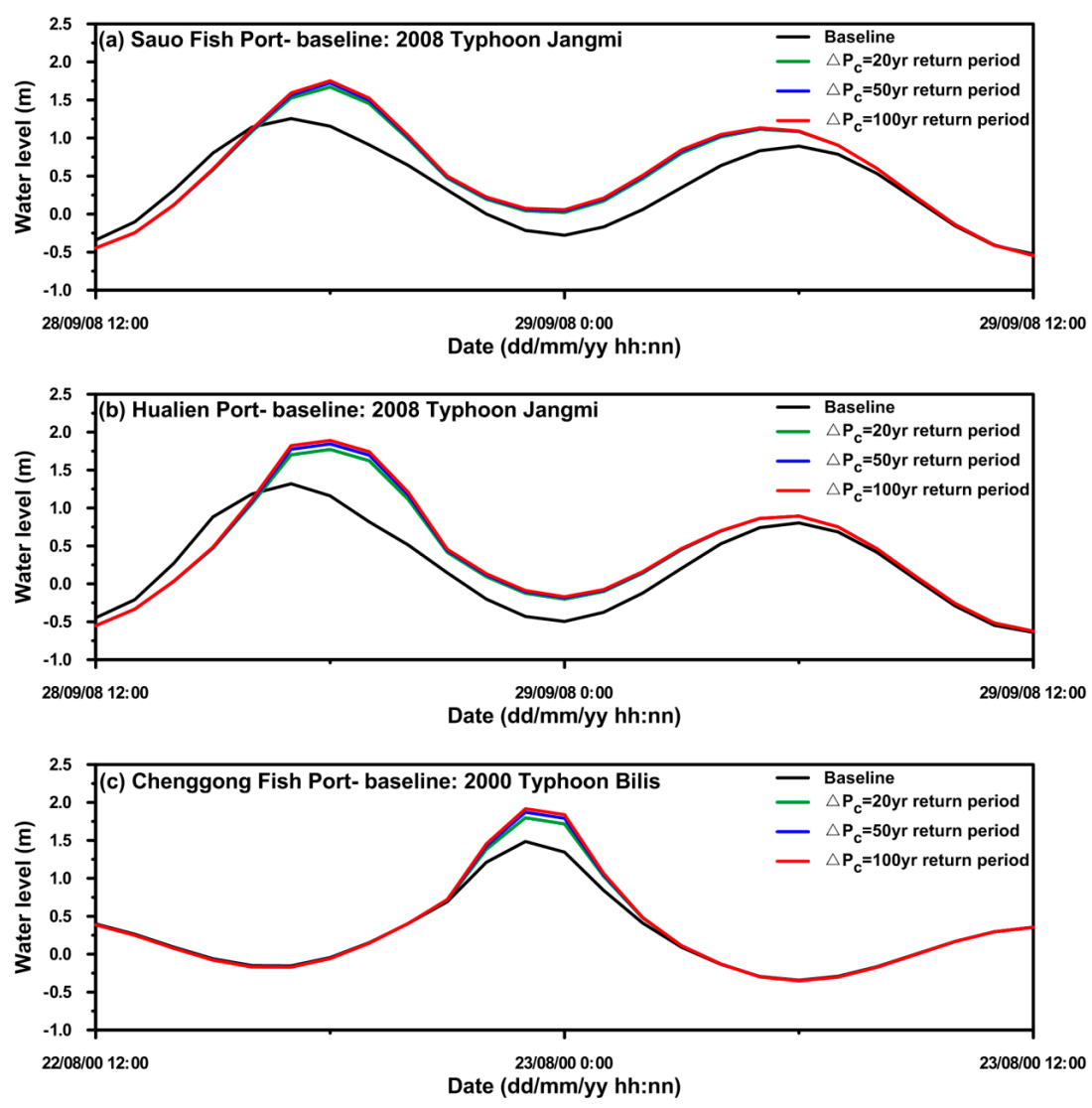

Figure 9. Comparison of simulated water level under baseline and $\Delta P_{c}$ specified with 20-year, 50 -year, and 100-year return periods at (a) Sauo Fish Port, (b) Hualien Port, and (c) Chenggong Fish Port.

Table 2. Computed $\Delta P_{c}$ in different return periods with the Weibull distribution.

\begin{tabular}{cccccc}
\hline \multirow{2}{*}{ Variable } & \multicolumn{5}{c}{ Return period (year) } \\
\cline { 2 - 6 } & 20 & 50 & 100 & 150 & 200 \\
\hline$\Delta P_{c}(\mathrm{mb})$ & 112.9 & 119.9 & 124.4 & 126.8 & 128.4 \\
$\left(P_{c}=1013.25-\Delta P_{c}(\mathrm{mb})\right)$ & $(900.35)$ & $(893.35)$ & $(888.85)$ & $(886.45)$ & $(884.85)$ \\
\hline
\end{tabular}

\subsection{Maximum Storm Tide Response to Bathymetric Change}

To investigate the influence of bathymetric changes on storm surges, three model experiments with bathymetry rising $50 \%, 70 \%$ and $90 \%$ in the entire computational domain were examined using the validated hydrodynamic model. Two baseline typhoons, Typhoon Bilis (2000) and Typhoon Jangmi (2008), were used in all of the scenario simulations. Figure 10 shows the water level hydrographs for Sauo Fish Port (Figure 10a), Hualien Port (Figure 10b), and Chenggong Fish Port (Figure 10c) using different bathymetric rise conditions. Figure 10 indicates that the maximum storm tide increases with rising bathymetry, particularly for the $90 \%$ bathymetric rise. It also can be observed that both positive and negative storm surges can be enlarged once the bathymetries become shallow. Weaver and Slinn [49] developed a one-dimensional analytical solution for waves and water level. They found that if the amplitudes of the bathymetric fluctuation are less than $60 \%$ of the original depth, the variation in the storm surge is within $\pm 10 \%$ of the original storm surge. Our model experiments for the storm tide response to bathymetric change are similar to the findings of Weaver and Slinn [49]. 
The meteorological forcing terms that affect storm surges include the wind stress and horizontal atmospheric pressure gradient. If we only consider the effects of the atmospheric pressure gradient on the water level with one-dimension, Eq. (2) can be simplified as:

$$
\Delta \eta=\frac{\Delta P_{A}}{\rho_{0} g}
$$

Eq. (17) reveals that the contribution of $\Delta P_{A}$ to the water level in the storm surge is irrelevant to the water depth. Dean and Dalrymple [50] explained that the water level in a storm surge is related to wind stress $\left(\tau_{s}\right)$, bottom stress $\left(\tau_{b}\right)$, and total water depth $(h+\eta)$ using a simple steady one-dimensional momentum equation:

$$
\frac{d \eta}{d x}=\frac{\left(\tau_{s}-\tau_{b}\right)}{\rho_{0} g(h+\eta)}
$$

As shown in Eq. (18), the water surface slope is proportional to the difference between wind stress and bottom stress and inversely proportion to the total water depth. If the difference between wind stress and bottom stress remains constant, the decreased water depth can result in an increased water level gradient. Flather and Williams [51] also documented that the water depth could influence the tidal component by changing its wavelength and modifying the propagation and dissipation of the tidal energy. The decreased water depth also affected the generation, propagation, and dissipation of the storm surge component, perhaps by slightly increasing the surge magnitude. According to the Eq. (18) and the report by Flather and Williams [51], we found that the tidal amplitude slightly increased at Soui Fish Port (Figure 10a), Hualien Port (Figure 10b) and Chenggong Fish Port (Figure 10c) due to the rising bathymetry (i.e., the decreasing water depth).

Another interesting phenomenon is that the phase of the tidal wave lags behind the baseline condition when the bathymetric rise reaches $90 \%$. Tidal waves are regarded as shallow water waves, and the tidal wave speed is independent of the wavelength [52]. The formula for the tidal wave speed, $c$, can be represented as:

$$
c=\sqrt{g H}
$$

The tidal wave speed, $c$, decreases as a result of a decrease in water depth, resulting in the phase lag shown in Figure 10.
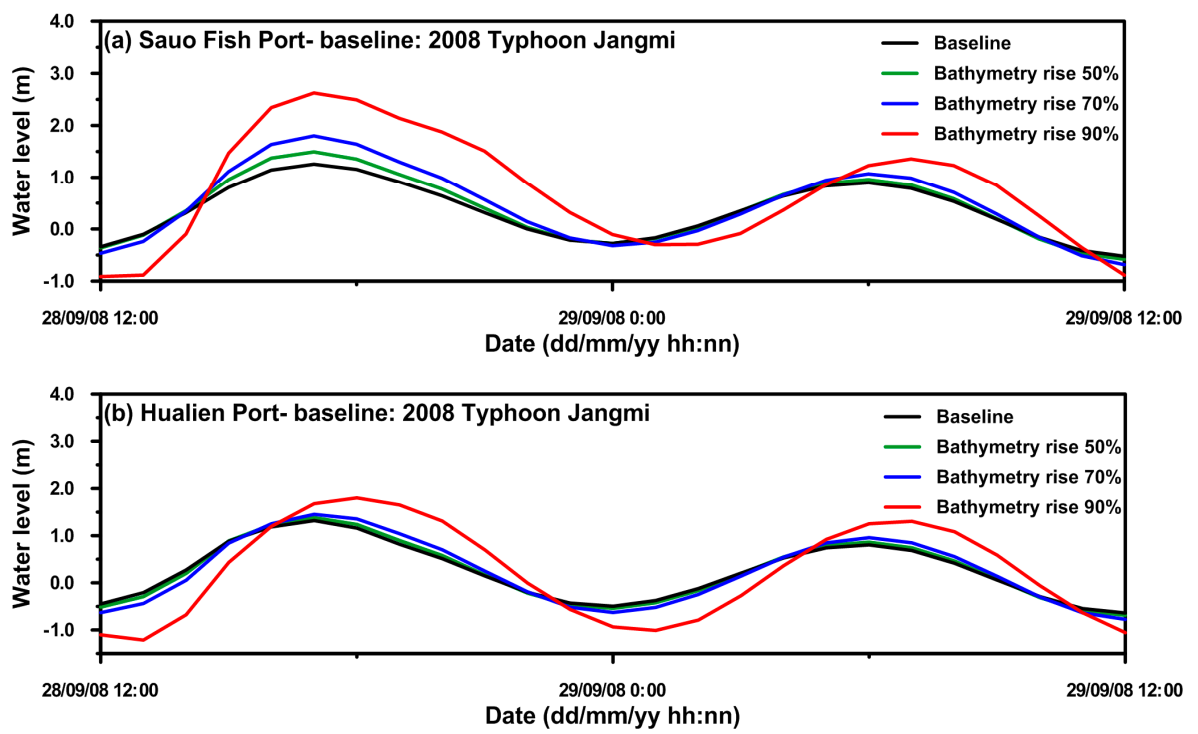


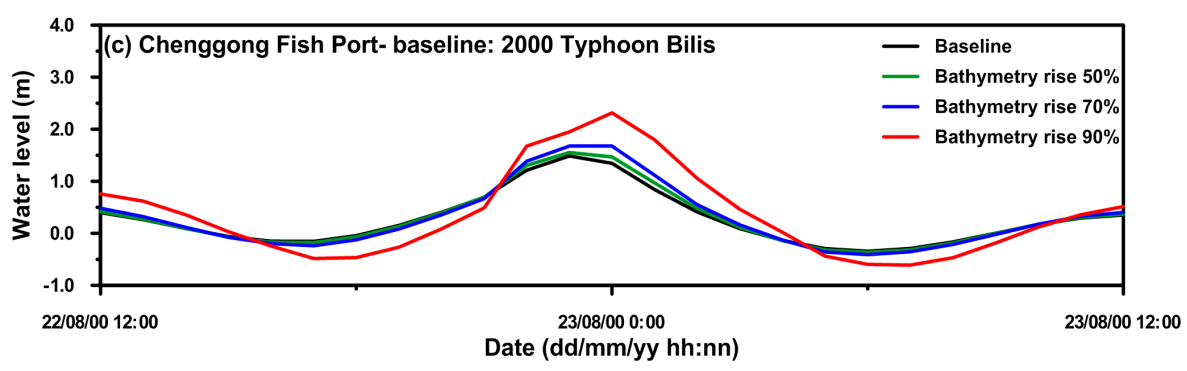

Figure 10. Comparison of simulated water levels under baseline and bathymetry rises of 50\%, 70\%, and $90 \%$ at (a) Sauo Fish Port, (b) Hualien Port, and (c) Chenggong Fish Port.

\subsection{The Combined Effect of a Typhoon's Intensity and Bathymetric Change}

To comprehend the influence of the combination of a typhoon's intensity and bathymetric change on storm surges, the combined effect of $\Delta P_{c}$ specified with a 100-year return period and a $90 \%$ bathymetric rise using the tracks of baseline typhoons were examined. Figure 11 illustrates the comparison of the simulated water level under baseline conditions and different scenarios. Figure 11 shows that that the maximum storm tides exceed $4 \mathrm{~m}, 2 \mathrm{~m}$, and $3 \mathrm{~m}$ at Sauo Fish Port, Hualien Port, and Chenggong Fish Port, respectively, as a result of the combination of $\Delta P_{c}$ specified with a 100-year return period and a $90 \%$ bathymetric rise. The maximum storm tide induced by a $90 \%$ bathymetric rise is higher than that induced by $\Delta P_{c}$ with a 100-year return period at Sauo Fish Port (Figure 11a) and Chenggong Fish Port (Figure 11c). Compared to the maximum storm tide induced by a $90 \%$ bathymetric rise and by $\Delta P_{c}$ with a 100-year return period, they are similar to Hualien Port (Figure 11b).

Figure 12 and Figure 13 show the distributions of the maximum storm tide in the horizontal plane under baseline conditions and different simulation scenarios, respectively, for Typhoon Bilis (2000) and Typhoon Jangmi (2008). We found that the combination of $\Delta P_{c}$ specified with a 100-year return period and a 90\% bathymetric rise produced the largest extent of storm tide (Figure 12d and Figure 13d). Compared to the baseline (Figure 12a and Figure 13a) and to $\Delta P_{c}$ specified with a 100 -year return period (Figure 12b and Figure 13b), the storm tides induced by a $90 \%$ bathymetric rise exhibit a longer (north-south) distribution along the shoreline (Figure 12c and Figure 13c) due to the shallower coast.
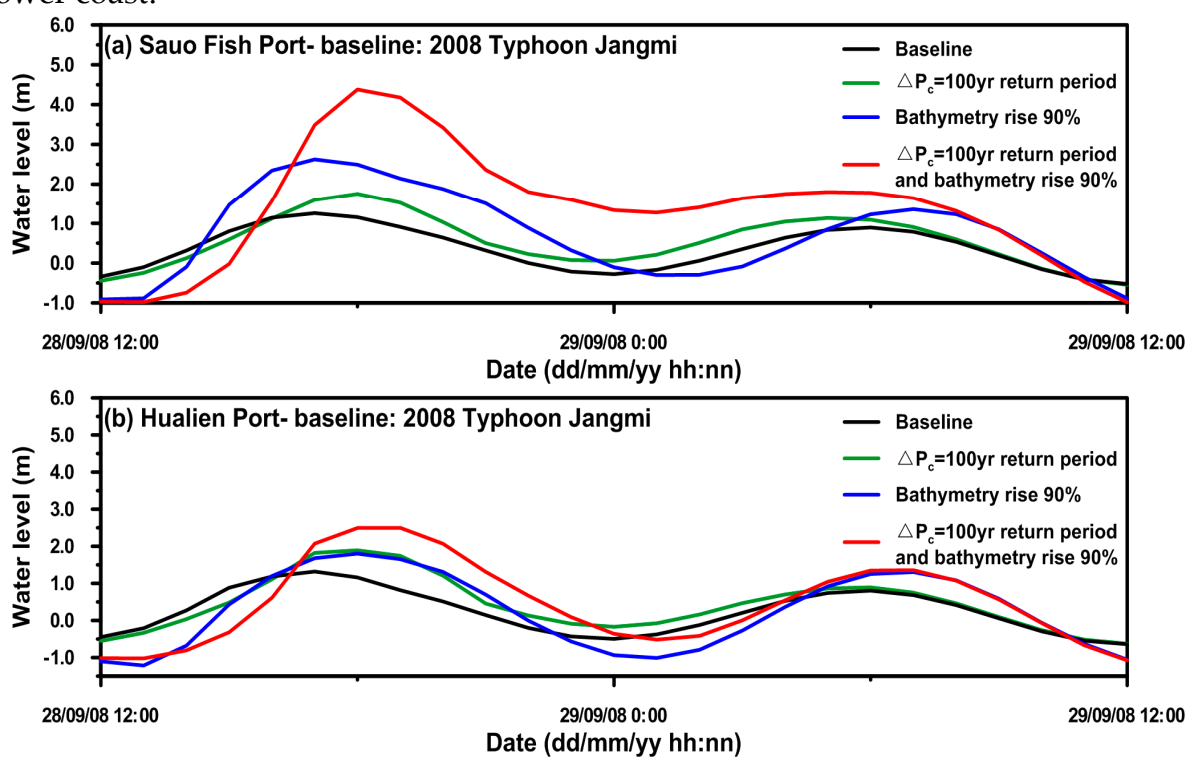


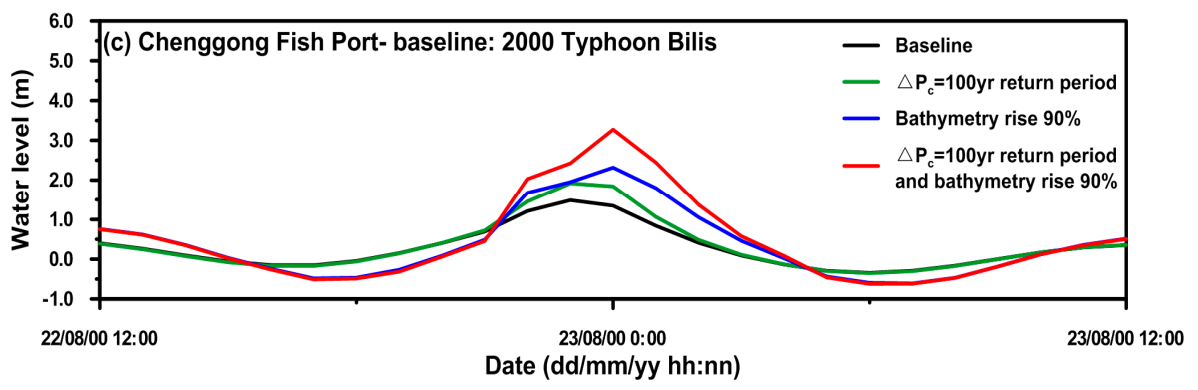

Figure 11. Comparison of the simulated water level under baseline, $\Delta P_{c}$ specified with a 100-year return period, $90 \%$ bathymetric rise, and the combination of $\Delta P_{c}$ specified with a 100-year return period and 90\% bathymetric rise at (a) Sauo Fish Port, (b) Hualien Port, and (c) Chenggong Fish Port.
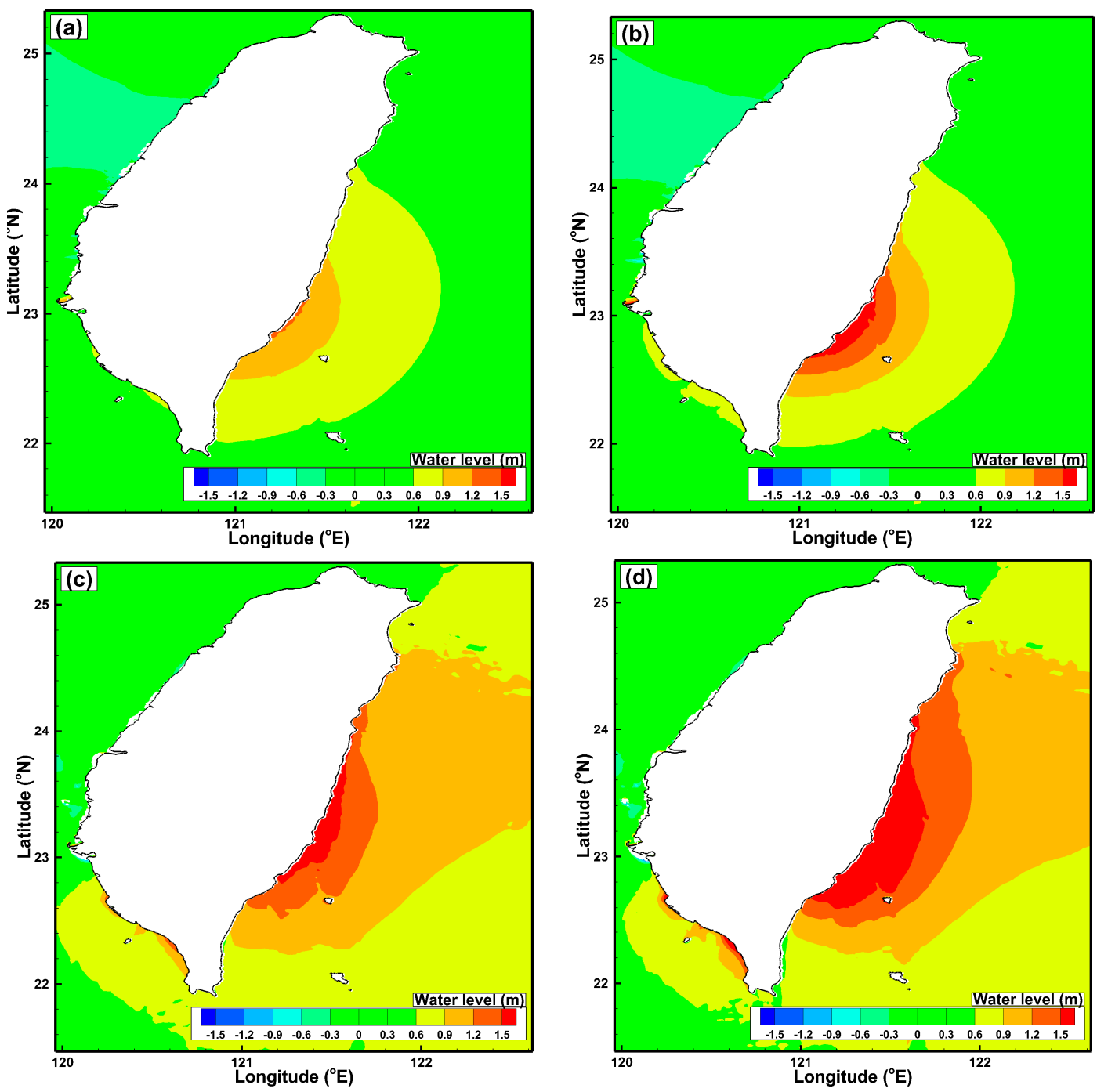

Figure 12. Simulated maximum storm tide distribution along the east coast of Taiwan for Typhoon Bilis (2000) under (a) baseline, (b) $\Delta P_{c}$ specified with a 100-year return period, (c) $90 \%$ bathymetric rise, and (d) the combination of $\Delta P_{c}$ specified with a 100 -year return period and $90 \%$ bathymetric rise. 

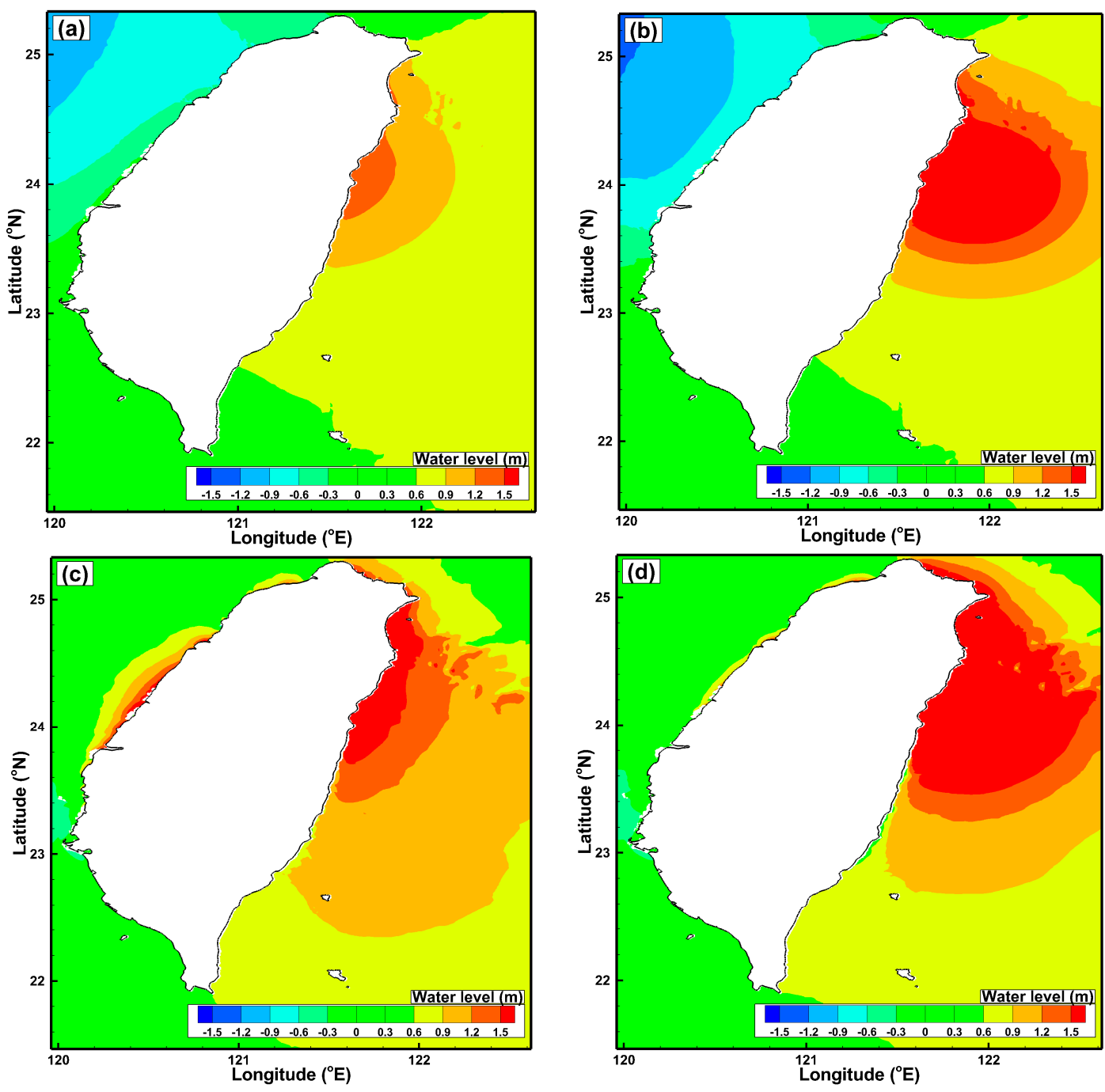

Figure 13. Simulated maximum storm tide distribution along the east coast of Taiwan for Typhoon Jangmi (2008) under (a) baseline, (b) $\Delta P_{c}$ specified with a 100 -year return period, (c) $90 \%$ bathymetric rise, and $(\mathrm{d})$ the combination of $\Delta P_{c}$ specified with a 100-year return period and $90 \%$ bathymetric rise

\section{Conclusions}

The two-dimensional hydrodynamic model, SELFE-2D, was implemented to simulate the storm tide along the coast of Taiwan. The model was validated with measured astronomical tides and storm tides at three tidal gauge stations for ten historical typhoon events. We found that the hydrodynamic model satisfactorily reproduced the tidal levels at Sauo Fish Port, Hualien Port, and Chenggong Fish Port, which are affected by astronomical tides and storm surges. The model is also capable of mimicking the maximum storm tide.

The frequency analysis was adopted to determine the pressure difference between the ambient pressure $(1013.25 \mathrm{mb})$ and the center pressure of a typhoon, $\Delta P_{c}\left(\Delta P_{c}=1013.25-P_{c}\right)$, for different return periods. The validated hydrodynamic model was then applied to investigate the maximum storm tide along the east coast of Taiwan in response to changes in the typhoon's intensity and bathymetry. The simulated results reveal that the maximum increment of the maximum storm tide reaches $0.57 \mathrm{~m}$ compared to the baseline condition, and $P_{c}$ reached $888.85 \mathrm{mb}$ for a typhoon 
with a 100-year return period at Hualien Port. The maximum storm tide increases as a result of rising bathymetry. The phase of the tidal wave lags behind the baseline condition when the bathymetric rise reaches $90 \%$. The maximum storm tides exceed $4 \mathrm{~m}, 2 \mathrm{~m}$, and $3 \mathrm{~m}$ at Sauo Fish Port, Hualien Port, and Chenggong Fish Port, respectively, as a result of the combination of $\Delta P_{c}$ from a typhoon with a 100-year return period and $90 \%$ bathymetric rise. The simulated results also indicate that the storm tides induced by the condition of $90 \%$ bathymetric rise produced a longer (north-south) distribution along the east coast of Taiwan.

Acknowledgments: This research was supported by the Ministry of Science and Technology (MOST), Taiwan, grant Nos. MOST 103-2635-M-239-002 and 104-2625-M-865-002. The authors appreciate the Central Weather Bureau, Taiwan, for providing the measured data and Dr. Joseph Zhang at the Virginia Institute of Marine Science, College of William \& Mary, for kindly sharing the SELFE code.

Author Contributions: Wen-Cheng Liu supervised the progress of the MOST projects and served as a general editor. We-Bo Chen and Lee-Yaw Lin performed the data collection, model establishment, and model simulations and discussed the results with Wen-Cheng Liu. All authors read and approved the final manuscript.

Conflicts of Interest: The authors declare no conflict of interest.

\section{References}

1. Gayathri, R.; Murty, P.L.N.; Bhaskaran, P.K.; Srinivasa Kumar, T. A numerical study of hypothetical storm surge and coastal inundation for AILA cyclone in the Bay of Bengal. Environ. Fluid Mech. 2016, 16, 429-452.

2. Loy, K.C.; Sinha, P.C.; Liew, J.; Tangang, F.; Husain, M.L. Modeling storm surge associated super typhoon durian in South China Sea. Nat. Hazard. 2014, 70, 23-37.

3. Rego, J.L.; Li, C. Storm surge propagation in Galveston Bay during Hurricane Ike. J. Mar. Syst. 2010, 82, 265-279.

4. Conner, W.C.; Kraft, R.H.; Harris, L.D. Empirical methods for forecasting the maximum storm tide due to hurricanes and other tropical storms. Mon. Weather Rev. 1957, 85, 113-116.

5. Horikawa, K. Coastal engineering. Tokyo University, Press, 1978.

6. Park, Y.H.; Suh, K.D. Variation of storm surge caused by shallow water depths and extreme tidal ranges. Ocean Eng. 2012, 55, 44-51.

7. Bhaskaran, P.K.; Nayak, S.; Bonthu, S.R.; Murty, P.L.; Sen, D. Performance and validation of a coupled parallel ADCIRC-SWAN model for THANE cyclone in the Bay of Bengal. Environ. Fluid. Mech. 2013, 13, 601-623.

8. Chen, W.B.; Liu, W.C.; Hsu, M.H. Computational investigation of typhoon-induced storm surges along the Coast of Taiwan. Nat. Hazard. 2012, 64, 1161-1185.

9. Resio, D.T.; Westerink, J.J. Modeling the physics of storm surges. Phys. Today 2008, 61, 33.

10. Xia, M.; Xia, L.; Pietrafesa, L.J.; Peng, M. A numerical study of storm surge in the Cape Fear River Estuary and adjacent coast. J. Coast. Res. 2008, 24, 159-167.

11. Xing, J.; Jones, E.; Davies, A.M.; Hall, P. Modelling tide-surge interaction effects using finite volume and finite element models of the Irish Sea. Ocean Dyn. 2011, 61, 1137-1174.

12. Yin, B.; Xu, Z.; Huang, Y.; Lin, X. Simulating a typhoon storm surge in the East Sea of China using a coupled model. Prog. Nat. Sci. 2009, 19, 65-71.

13. You, S.H.; Lee, W.J.; Moon, K.S. Comparison of storm surge/tide predictions between a 2-D operational forecast system, the regional tide/storm surge model (RTSM), and the 3-D regional ocean modeling system (ROMS). Ocean Dyn. 2010, 60, 443-459.

14. Xu, S.; Huang, W.; Zhang, G.; Gao, F.; Li, X. Integrating Monte Carlo and hydrodynamic models for estimating extreme water levels by storm surge in Colombo, Sri Lanka. Nat. Hazard. 2014, 71, 703-721.

15. Murty, P.L.N.; Sandhya, K.G.; Bhaskaran, P.K.; Jose, F.; Gayathri, R.; Nair, T.M.B.; Kumar, T.S.; Shenoi, S.S.C. A coupled hydrodynamic modeling system for PHAILIN cyclone in the Bay of Bengal. Coast. Eng. 2014, 93, 71-81.

16. Marujo, N.R.C.S.; Araujo, M.A.V.; Trigo-Teixeira, A.; Falcao, A.P.; Mazzolari, A. Storm-surge hindcast at Viana do Castelo: An oceanic and estuarine domain approach. J. Coast. Res. 2004, 30, 1268-1277. 
17. Drews, C.D.; Galameau, T.J. Directional analysis of the storm surge from Hurricane Sandy 2012, with applications to Charleston, New Orleans, and the Philippines. PLos ONE 2015, 10, e0122113.

18. Zhang, H.; Sheng, J. Examination of extreme sea levels due to storm surges and tides over the northwest Pacific Ocean. Cont. Shelf Res. 2015, 93, 81-97.

19. Arns, A.; Wahl. T.; Dangendrof, S.; Jensen, J. The impact of sea level rise on storm surge water levels in the northern part of the German Bight. Coast. Eng. 2005, 96, 118-131.

20. Zhang, X.J.; Wang, D.G.; Lai, X.J.; Song, H.H. Effect of forecasted typhoon track uncertainties on storm surge predictions for the coast of Shanghai. J. Hydraul. Res. 2016, 54, 41-55.

21. Shen, J.; Zhang, K.; Xiao, C.; Gong, W. Improved prediction of storm surge inundation with a high-resolution unstructured grid model. J. Coast. Res. 2006, 22, 1309-1319.

22. Amante, C.; Eakins, B.W. ETOPO1 1 arc-minute global relief model: procedures, data sources and analysis. NOAA Technical Memorandum NESDIS NGDC-24, National Geophysical Data Center, NOAA, 2009. doi:10.7289/V5C8276M.

23. Zhang, Y.J.; Baptista, A.M. SELFE: A semi-implicit Eulerian-Lagrangian finite-element model for cross-scale ocean circulation. Ocean Model. 2008, 21, 71-96.

24. Zhang, Y.J.; Witter, R.C.; Priest, G.R. Tsunami-tide interaction in 1964 Prince William Sound tsunami. Ocean Model. 2011, 40, 246-259.

25. Rodrigues, M.; Oliveira, A.; Queiroga, H.; Fortunato, A.B.; Zhang, Y.J. Three-dimensional modeling of the lower trophic levels in the Ria de Aveiro (Portugal). Ecol. Model. 2009, 220, 1274-1290.

26. Azevedo, A.; Oliveira, A.; Fortunato, A.B.; Bertin, X. Application of an Eulerian-Lagrangian oil spill modeling system to the prestige accident: trajectory analysis. J. Coast. Res. 2011, SI 56, 777-781.

27. Fortunato, A.B.; Rodrigues, M.; Dias, J.M.; Lopes, C.; Oliveira, A. Generating inundation maps for a coastal lagoon: A case study in the Ria de Aveiro (Portugal). Ocean Eng. 2013, 64, 60-71.

28. Chen, W.B.; Liu, W.C. Modeling flood inundation Induced by river flow and storm surges over a river basin. Water 2014, 6, 3182-3199.

29. Wang, H.V.; Loftis, J.D.; Liu, Z.; Forrest, D.; Zhang, J. The storm surge and sub-grid inundation modeling in New York City during hurricane Sandy. J. Mar. Sci. Eng. 2014, 2, 226-246.

30. Large, W.G.; Pond, S. Open ocean momentum flux measurements in moderate to strong winds. J. Phys. Oceanogr. 1981, 11, 324-336.

31. Powell, M.D.; Vickery, P.J.; Reinhold, T.A. Reduced drag coefficient for high wind speeds in tropical cyclones. Nature 2003, 422, 279-283.

32. Egbert, G.D.; Bennett, A.F.; Foreman, M.G.G. Topex/poseidon tides estimated using a global inverse model. J. Geophys. Res. 1994, 99(C12), 821-852.

33. Egbert, G.D.; Erofeeva, S.Y. Efficient inverse modeling of barotropic ocean tides. J. Atmos. Ocean Tech. 2002, 19, 183-204.

34. Fujita, T, Pressure distribution in typhoon. Geophys. Magaz. 1952, $23,437$.

35. Holland, G.J. An analytical model of the wind and pressure profiles in hurricanes. Mon. Weather Rev. 1980, 108, 1212-1218.

36. Jelesnianski, C.P. A numerical computation of storm tides induced by a tropical storm impinging on a continental shelf. Mon. Weather Rev. 1965, 93, 343-358.

37. MacAfee, A.W.; Pearson, G.W. Development and testing of tropical Cyclone parametric wind models tailored for midlatitude application-preliminary results. J. Appl. Meteorol. Climat. 2006, 45, 1244-1260.

38. Wood, V.T.; White, L.W.; Willoughby, H.E.; Jorgensen, D.P. A new parametric tropical cyclone tangential wind profile model. Month. Weather Rev. 2013, 141, 1884-1909.

39. Jakobsen, F.; Madsen, H. Comparison and further development of parametric tropical cyclone models for storm surge modelling. J. Wind Eng. Ind. Aerod. 2004, 92, 375-391.

40. Hubbert, G.D.; Holland, G.J.; Leslie, L.M.; Manton, M.J. A real-time system for forecasting tropical cyclone storm surges. Weather Forecast. 1991, 6, 86-97.

41. Gumbel, E.J. Statistics of extremes. Columbia University Press, 375 pp, 1958.

42. Weibull, W. A statistical distribution function of wide applicability. J. Appl. Mech. 1951, 18, $293-297$.

43. Gupta, H.V.; Sorooshian, S.; Yapo, P.O. Status of automatic calibration for hydrologic models: comparison with multilevel expert calibration. J. Hydrol. Eng. 1999, 4, 135-143. 
44. Moriasi, D.N.; Arnold, J.G.; Van Liew, M.W.; Bingner, R.L.; Harmel, R.D.; Veith, T.L. Model evaluation guidelines for systematic quantification of accuracy in watershed simulations. Am. Soc. Agric. Biologic. Eng. 2007, 50, 885-900.

45. Feng, W.; Yin, B.; Yang, D. Effect of hurricane paths on storm surge response at Tianjin, China. Estuar. Coast. Shelf Sci. 2012, 106, 58-68

46. Fujii, T. Statistical analysis of the characteristics of severe typhoon hitting the Japanese main islands. Mon. Weather Rev. 1998, 126, 1901-1907.

47. Irish, J.L.; Resio, D.T.; Ratcliff, J.J. The influence of storm size on hurricane surge. J. Phys. Oceanogr. 2008, 38, 2003-2013.

48. Bernier, N.B.; Thompson, K.R. Predicting the frequency of storm surges and extreme sea levels in the Northwest Atlantic. J. Geophys. Res. 2006, 111, C10009.

49. Weaver, R.J.; Slinn, D.N. Influence of bathymetric fluctuations on coastal storm surge. Coast. Eng. 2010, 57, 62-70.

50. Dean, R.G.; Dalrymple, R.A. Coastal processes with engineering applications. Cambridge University Press, UK, 2004. Feng, W.; Yin, B.; Yang, D. Effect of hurricane paths on storm surge response at Tianjin, China. Estuar. Coast. Shelf Sci. 2012, 106, 58-68.

51. Flather, R.A.; Williams, J.A. Climate change effects on storm surges: methodologies and results. In: Climate Scenarios for Water-related and Coastal Impact, Edits by Beersma J, Agnew M, Viner D, Hulme M, ECLAT-2 Workshop Report No. 3, 66-78. The Netherlands: KNMI, 2002.

52. Kundu, P.K. Fluid mechanics, Academic Press Inc., U.S, 1990.

(C) 2017 by the authors. Licensee Preprints, Basel, Switzerland. This article is an open access article distributed under the terms and conditions of the Creative Commons by Attribution (CC-BY) license (http://creativecommons.org/licenses/by/4.0/). 